\title{
GESTÃO AMBIENTAL NA ESCOLA: ESTRATÉGIAS PEDAGÓGICAS PARA FORMAÇÃO DOCENTE E DISCENTE
}

Carla Fabiana Silveira Moro ${ }^{1}$

Cintia Soares Guerin ${ }^{2}$

Cadidja Coutinho 3

Resumo: O presente trabalho teve por objetivo investigar as concepções de docentes e discentes sobre a Gestão Ambiental (GA), no intuito de trabalhar conceitos e práticas para um Sistema de Gestão Ambiental (SGA) fundado no uso de tecnologias limpas e Educação Ambiental (EA). Para tanto, a metodologia foi desenvolvida por meio da pesquisa qualitativa. Diversos tipos de ferramentas foram usados, entre eles: questionários, formação docente, práticas interdisciplinares, sensibilização da comunidade e oficinas teóricopráticas. Pode-se concluir que, discentes e docentes se encontram carentes de conhecimento sobre GA e EA e, que a ampliação de formações e trabalhos nesta área podem influenciar positivamente no manejo dos recursos naturais renováveis e na redução dos resíduos.

Palavras-chave: Gerenciamento Ambiental; Educação Ambiental; Espaço Escolar.

1 Universidade Regional Integrada do Alto Uruguai e das Missões - URI - Santiago (RS) - Brasil. E-mail: carla.moro@urisantiago.br

2 Universidade Regional Integrada do Alto Uruguai e das Missões - URI - Santiago (RS) - Brasil. E-mail: cintiaguerin@hotmail.com

3 Universidade Regional Integrada do Alto Uruguai e das Missões - URI - Santiago (RS) - Brasil. E-mail: cadidjabio@gmail.com 


\section{Introdução}

Está cada vez mais evidente o espaço que a proposta de sustentabilidade vem conquistando na esfera educacional. A sua inclusão nos currículos educacionais é assunto de ampla discussão por diferentes pesquisas - a exemplo de Teixeira et al. (2016) e Brisolara (2016). O foco de tais pesquisas, conforme indicam Vehzke e Nascimento (2013), consiste no nível de atuação dos sistemas, na promoção de conhecimentos relacionados ao tema, bem como, no incentivo às ações de caráter estratégico, que possibilitam a sustentabilidade.

Atualmente, termos como ecologia, meio ambiente e manejo sustentável dos recursos naturais renováveis têm sido, frequentemente, citados e discutidos nos mais variados espaços da sociedade. Todavia, verifica-se mínima a parcela da população que é contemplada com conhecimentos acerca destes temas, incapacitando o entendimento da dinâmica e das inter-relações que ocorrem entre os diferentes ecossistemas existentes (SCHWERZ, 2016). Com efeito, faz-se necessária trabalhar a sensibilização ambiental, garantindo que todas as camadas sociais tenham acesso informação e conhecimento, que até então vem lhe sendo relegado.

Nessa perspectiva, Fehlberg et al. (2014), destaca-se que o conceito de sustentabilidade é um tema importante para ser trabalhado nas escolas, principalmente no Ensino Fundamental (EF), momento em que as crianças vivenciam suas primeiras experiências com as questões relacionadas ao meio ambiente. Momento esse que possibilita aos professores ensinar aos alunos sobre a importância da preservação do meio ambiente, especialmente no que tange à garantia da sobrevivência das futuras gerações.

Fehlberg et al. (2014), afirmam, ainda, que novas práticas educativas vêm surgindo em razão da necessidade de um ensino democrático e construtivo, baseado em uma visão crítica e em um olhar mais profundo sobre a problemática ambiental. Dessa forma, percebe-se que cada vez mais se abrem portas para uma renovação pedagógica, onde o direito à educação não se limitará ao acesso à escola, mas sim, transformará ambiente em que a criança está inserida em uma verdadeira extensão escolar, em que a comunidade integra o processo de ensino-aprendizagem e 0 aluno passa a relacionar as práticas ambientais ao exercício de cidadania.

Com efeito, a Gestão Ambiental (GA) envolve práticas que visam garantir a conservação, a preservação e a redução do impacto ambiental das atividades humanas sobre os recursos naturais, que podem ser trabalhadas em empresas públicas ou privadas, indústrias e instituições de ensino (MATURANO, 2010). Nesse mesmo sentido, a escola, como instituição social, ao aplicar práticas pedagógicas que estejam em conformidade com os princípios da Educação Ambiental, torna-se agente impulsor de uma convivência sustentável, por meio da elaboração de um plano de Gestão Ambiental Escolar (SILVA, 2017). 
Dentro das práticas de GA, encontra-se o Sistema de Gestão Ambiental (SGA) que é voltado principalmente à Educação Ambiental e que colabora para o melhoramento da instituição escolar, favorecendo a compreensão desta temática, promovendo a interdisciplinaridade, orientando a comunidade escolar na organização das ações quanto à necessidade da preservação e da manutenção ambiental (NUNES; CARVALHO, 2014).

Nesse sentido, é relevante compreender a GA como parte integradora e multidisciplinar na escola e atentar que a Educação Ambiental está diretamente associada ao Tema Transversal "Meio Ambiente", proposto pelos Parâmetros Curriculares Nacionais (PCN) desde o ano de 1997.

Assim, entende-se que a EA deveria ser elemento integrante da transformação social, pois baseada no diálogo, no exercício da cidadania, no fortalecimento dos sujeitos, na compreensão do mundo em sua complexidade e da vida em sua totalidade (LOUREIRO, 2002).

Neste contexto, afirma-se a escola como local irradiador e mediador do saber, em prol do desenvolvimento da comunidade por meio de seus próprios atores, qual sejam, os alunos, professores, pais e gestores. Perspectiva, a qual, demonstra que a escola possui, também, papel indispensável na formação de cidadãos éticos e ambientalmente responsáveis.

Assim, no compromisso de formar uma sociedade mais consciente e capaz de compreender a realidade social, a Educação Ambiental (EA) vem como alternativa viável a ser trabalhada em salas de aula. Isso porquê, são diversos os aspectos que podem ser abordados, sejam eles ecológicos, econômicos e sociais, garantindo, assim, uma visão multifacetada das questões socioambientais, que visivelmente se fazem presentes em todas as disciplinas escolares.

Entende-se que são diversas as dificuldades encontradas para efetivação de mudanças na prática escolar e, no que tange à Educação Ambiental, visualiza-se a ideia de que este tema é pertinente apenas em aulas de Ciências e Biologia, somando-se à ausência de recursos didáticos, elevado número de alunos por sala e, ainda, maior ênfase à transmissão de informações e elaboração de políticas institucionais que, em sua maioria, não direcionam para ações educativas centradas na mudança de atitudes e valores (CARVALHO, 2012).

Desta forma, práticas simples de abordagem das questões ambientais, como reaproveitamento e reciclagem, têm sido trabalhadas em sala de aula, mas tal questões ainda estão distantes de um entendimento real. Nesse sentido, devem ser trabalhados o uso de tecnologias limpas e sua aplicabilidade, que trata da utilização de tecnologias que proporcionem um menor consumo de recursos naturais (água, energia e outros produtos), minimizando resíduos, riscos e impactos ambientais (ANDRADE; MARINHO; KIPERSTOK, 2004). Bem como, a reutilização de resíduos sólidos, reaproveitamento de óleo de cozinha, promovendo uma efetiva sensibilização e 
atuação do cidadão "comum", direcionada a reduzir os impactos ambientais causados pelo consumo.

Assim, por meio do presente trabalho, investigar as concepções de docentes e discentes sobre a GA, a fim de trabalhar conceitos e práticas para um SGA baseado no uso de tecnologias limpas e EA, questionando-se como tornar a escola um espaço para efetivação da Gestão Ambiental (GA) e como tem se dado a GA na escola.

\section{Metodologia}

A abordagem utilizada no desenvolvimento deste estudo foi a qualitativa e a coleta de dados ocorreu no período de março a novembro de 2016, na Escola Municipal de Ensino Fundamental Mariúza Silva da Silva, localizada no município de Itacurubi, Rio Grande do Sul (RS).

Foram convidados a participar do projeto docentes e discentes da referida escola, sendo que houve a participação efetiva de 27 (vinte e sete) professores e 201 (duzentos e um) estudantes, distribuídos em turmas do Ensino Fundamental e, além destes, a comunidade em geral.

O presente estudo foi desenvolvido em quatro etapas: (i) primeiro contato com a instituição; (ii) desenvolvimento de oficinas teórico-práticas com os docentes; (iii) envolvimento dos alunos/discentes com atividades teóricopráticas; (iv) realização de oficinas e integração com a comunidade.

Durante a primeira etapa, foram realizadas reuniões com a administração da instituição para apresentação da proposta, bem como, das ações a serem realizadas, seu respectivo o cronograma, organização das turmas e o envolvimento da comunidade.

Na segunda etapa, houve a apresentação do tema "Gestão Ambiental" corpo docente. Para aferir uma avaliação inicial do conhecimento dos envolvidos foram distribuídos questionários (Apêndice $A$ ), realizando-se assim a coleta de dados.

Bem como, foi indagado aos participantes a seguinte questão: "Para você o que é Meio Ambiente?". Os docentes responderam o questionamento por meio de bilhetes e, em seguida, foi montando um cartaz com o material produzido. Conforme o roteiro pré-estabelecido, dividido em dois momentos, sendo o primeiro teórico, passou-se à abordagem dos conhecimentos acerca da GA e do SGA e, em seguida à prática, realizada com a distribuição de diferentes gravuras sobre meio ambiente aos participantes, que se reuniram em grupos e elaboraram planos de ação para desenvolver os temas sugeridos nas gravuras, em suas disciplinas específicas.

Após a realização das discussões e do desenvolvimento dos planos em grupo, procedeu-se à socialização das ideias construídas ao grupo geral, possibilitando o diálogo e a sugestão de novas ideias. 
$\mathrm{Na}$ realização da terceira etapa da pesquisa, os professores foram orientados a trabalhar com alunos do $1^{\circ}$ ao $9^{\circ}$ ano da escola, subdivididos de acordo com os ciclos do Ensino Fundamental (EF): $1^{\circ}$ ciclo ( $1^{\circ}$ ao $3^{\circ}$ ano); $2^{\circ}$

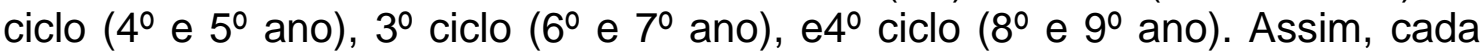
ciclo possuía um professor responsável.

Aos estudantes foi igualmente distribuído um questionário (Apêndice $B$ ) para coleta de dados sobre o tema. $O$ referido questionário foi elaborado de uma forma lúdica e de fácil compreensão, utilizando-se de símbolos, buscando abranger as diferentes idades entre os alunos.

A proposta, a seguir, foi compartilhar as informações recebidas sobre GA e SGA com os estudantes, de forma teórico-prática, abordando temas como: a importância do papel e de onde ele vem; cuidados com o lixo; criação de uma horta, clarificando conceitos como de lixo seco e orgânico; caracterização dos materiais, identificando o que pode ser reciclado/reutilizado; e, o reaproveitamento de óleo vegetal usado.

De posse dos conhecimentos sobre GA, SGA, Tecnologias Limpas e $E A$, os alunos, juntamente com o professor-tutor, estabeleceram um plano de reaproveitamento de óleo de cozinha, para a fabricação de sabão, através do SGA, envolvendo-se na coleta de óleo usado, que veio a ser armazenado na escola, sensibilizando outro nicho na participação do SGA - a comunidade local do município.

$\mathrm{Na}$ quarta e última etapa, cada ciclo do EF participou de uma atividade prática sobre GA. Inicialmente, houve uma breve explicação sobre os conceitos relacionados ao meio ambiente, sua preservação e degradação, meios de redução de resíduos, reciclagem, entre outras. Em seguida, foi realizada a fabricação de sabão, que foi ponto culminante de integração de toda a comunidade escolar na implantação do SGA, pois o óleo usado foi doado por pais e moradores do entorno escolar.

No intuito de sondar o aproveitamento das atividades desenvolvidas na presente pesquisa, aplicou-se um questionário final sobre GA e SGA (Apêndice C), respondido por 65 (sessenta e cinco) alunos dos supracitados ciclos/anos.

O presente trabalho foi submetido ao Comitê de Ética em Pesquisa da URI Campus Santiago e, somente realizado após a aprovação do mesmo conforme resolução 466/12.

\section{Resultados e discussão}

Participaram do estudo 27 (vinte e sete) docentes, do sexo feminino, com idade compreendida entre 30 e 61 anos.

As docentes efetuam suas atividades em diferentes áreas de conhecimento, sendo distribuídas da seguinte maneira: 4 (quatro) lecionam a disciplina de língua portuguesa; 3 (três) professoras de matemática; 2 (duas) exercem atividades em ciências, 1 (uma) professora de história e geografia; 14 
(quatorze) professoras que trabalham com a educação infantil e 3 (três) fazem parte do grupo gestor da escola.

Também participaram da pesquisa estudantes dos 4 ciclos do Ensino Fundamental, com idades compreendidas em entre 6 (seis) a 15 (quinze) anos, bem como, a comunidade escolar externa.

\section{Contexto docente: 0 processo formativo para a sustentabilidade}

Inicialmente, o questionário aplicado às docentes, referente aos tipos de estratégias aplicadas em sala de aula, pode-se perceber que as propostas de projetos e atividades lúdicas foram as mais mencionadas.

Sendo assim, infere-se que os educadores preferem envolver os alunos com as atividades, tornando-os atores do processo de aprendizagem, corroborando Freire (2011, p.121), no Livro "Pedagogia da Autonomia":

(...) É preciso que a escola instigue constantemente a curiosidade do educando (...) É preciso, por outro lado, e sobretudo, que o educando vá assumindo o papel de sujeito da produção de sua inteligência do mundo e não apenas o de receber da que lhe seja transferida pelo professor.

As professoras apontaram assuntos sobre reciclagem, água e lixo, como os mais significativos para tratar GA na escola, tendo em vista que são temas de amplo conteúdo e grande importância para a manutenção do ambiente. Contudo, de posse da autonomia do ser professor e do ser estudante, infere-se que a temática Meio Ambiente pode ser trabalhada em diversas e diferentes esferas, entretanto as atividades sugeridas e elaboradas pelas professoras foram, basicamente, voltadas à reciclagem e 0 reaproveitamento de resíduos, confirmando as propostas desta pesquisa.

Por meio da análise dos 27 (vinte e sete) questionários respondidos pelas professoras, pode-se constatar que $41 \%$ (quarenta e um por cento) das docentes participaram de formações sobre o tema Meio Ambiente e 66\% (sessenta e seis por cento) responderam que são poucas as ações de sustentabilidade realizadas na escola.

Quando interrogadas sobre seu conhecimento individual em relação à GA, $56 \%$ (cinquenta e seis por cento) das professoras mencionaram possuir pouco conhecimento sobre a temática. $E$, ainda, $59 \%$ (cinquenta e nove por cento) das docentes responderam que a escola realiza poucos encontros e/ou palestras sobre o tema de GA. Por fim, 52\% (cinquenta e dois por cento) afirmaram que desenvolvem poucas atividades sobre GA no decorrer de suas aulas.

As professoras se mostraram instigadas pelo tema, mesmo que, em um primeiro momento, este lhes tenha parecido alheio aos seus conhecimentos e/ou interesses.

revista brasileira educação ambiental 
Verifica-se que a falta de incentivo em relação às questões socioambientais nas formações e cursos, é elemento indicativo sobre às dificuldades perpassadas, o motivo pelo qual se faz necessário estudar e trabalhar de maneira contínua e intensa com os(as) docentes nas escolas públicas de educação básica, com vistas à GA e à EA escolar.

Assim, entende-se que a própria escola tem dever de incentivar a comunicação entre as diversas áreas do saber, auxiliando à quebra das fronteiras que reprimem a aprendizagem como um todo. Quanto ao professor, cabe empreender na busca de uma educação eficaz e integrada, desfragmentada, que auxilie na formação dos alunos como um todo inseparável, que possua como objetivo primordial, a construção dos indivíduos para uma cidadania planetária, em direção a um mundo melhor e mais justo (MORIN, 2005).

A pergunta aplicada na primeira etapa da pesquisa "Para você o que é Meio Ambiente?" foi respondida pelo grupo por meio de conceitos, que foram escritos em folhetos. Estes foram colados em um cartaz e posteriormente socializados. A fim de otimizar a interpretação, as respostas foram classificadas e com os respectivos exemplos a seguir:

- Natureza - "É o meio em que estamos inseridos. As plantas, os animais, a água, o solo, tudo que nos cerca com a participação do homem". espaço".

Território - "Mundo onde nós vivemos"; "É tudo que compõe o

- Vida - "O meio ambiente é como um todo. A vida, tanto a vida humana, animal ou vegetal".

Todas as respostas foram consideradas, pois condiziam com os conceitos já estabelecidos em diferentes pesquisas, à exemplo de Barbieri (2011, p.1), que afirma:

Entende-se por Meio Ambiente, o natural e o artificial, ambiente físico e biológico originais, e o que foi alterado, destruído e construído pelos humanos. Além de ser o espaço onde os seres vivos existem, é também a própria condição para a vida na Terra.

Em seguida, foram apresentadas considerações sobre a temática ambiental, noções de GA e SGA, momento em que houve grande envolvimento das participantes. As professoras foram instruídas sobre os procedimentos para implementação de um SGA, baseado na NBR ISO 14001 e ISO 14004, que pode ser aplicado em qualquer empresa, inclusive no caso das instituições de ensino. Ainda, receberam orientações referentes a quais passos seguir para 
a aplicação de um SGA e de como realizá-lo envolvendo os diversos atores do ambiente escolar.

Neste contexto, observa-se a crescente inserção da temática ambiental na educação básica, entretanto os professores apresentam dificuldades diante das exigências que lhes são impostas. Contudo, não podem ser responsabilizados diretamente por isso, tendo em vista que a formação inicial, especialmente as licenciaturas, pouco contribui para estes temas, não oferecendo os ensinamentos necessários sobre a EA.

Diante disso, Manzano (2003, p.10) infere que:

(...) os professores das séries iniciais do Ensino Fundamental têm apresentado uma formação, em geral, deficiente em conteúdos específicos. Apesar da dedicação desses profissionais, carecem de estudos sobre a presença de atividades, projetos e ações sobre o tema meio ambiente em suas práticas, bem como sobre a origem das informações utilizadas por esses professores em sua atividade docente.

Neste sentido, cabe ressaltar a relevância da formação docente, pois o professor necessita estar preparado pedagogicamente para mediar a construção do conhecimento. Isso porquê, por meio dos professores que se estabelece o laço entre a escola, os alunos e a comunidade, tratando-se da efetividade da proposta ambiental sugerida pelo projeto.

A complexidade do "Ser Professor" tem respaldo no seu próprio exercício docente (CUNHA, 2006; SEVERINO, 2006). A significativa construção do conhecimento se configura quando as práticas profissionais são voltadas a garantir a aprendizagem dos alunos, com condições singulares, multiplicidade de saberes, competências e habilidades para reconhecer o específico, em suas relações multifacetadas, sem mera transmissão de conteúdos. Mesmo que o domínio do conhecimento específico assegure a transposição de saberes para efetiva aprendizagem, o conhecimento amplo e interdisciplinar, bem como diferentes saberes pedagógicos, são essenciais no processo de ensinar e aprender.

Dessa forma, com a realização da oficina, foi possibilitado às docentes pensar a EA de maneira interdisciplinar. A utilização das gravuras relacionadas ao tema, as propostas práticas para o trabalho em sala de aula, com os mais diferentes níveis de alunos, puderam reforçar a ideia de que a EA não é papel exclusivo da disciplina de ciências e que pode e deve ser desenvolvida em todas as áreas do conhecimento.

E é na formação permanente dos professores que se faz possível a melhoria em ampliação dos conhecimentos sobre EA, pois o ensinar exige reflexão crítica sobre a prática, sendo este um momento fundamental. É pensando criticamente a prática de hoje ou de ontem que se pode melhorar a próxima prática (FREIRE, 2011).

revista brasileira educação ambiental 
Conforme se pode aferir da análise dos trabalhos desenvolvidos e sobre a sua respectiva socialização, momento em que ocorreu compartilhamento de ideias, observou-se que as figuras ilustrativas sobre Meio Ambiente, sua depreciação ou preservação, geraram diferentes métodos de abordagem no tocante ao trabalho sobre EA para à sala de aula.

Baseado nas reflexões, citam-se algumas sugestões apresentadas pelo grupo docente, em diferentes disciplinas (Quadro 1).

Quadro 1: Temas sobre Educação Ambiental para abordagem em sala de aula.

\begin{tabular}{l|l}
\multicolumn{1}{c|}{ DISCIPLINA } & \multicolumn{1}{|c}{ TEMÁTICAS E PROPOSTAS DE ATIVIDADES } \\
\hline Educação Infantil & $\begin{array}{l}\text { Desenhos; cartazes, "contação" de histórias, produção de textos, práticas } \\
\text { ambientais no pátio da escola, produção de composteira; separação do } \\
\text { lixo; fantoches com peças teatrais; pintura e colagem. }\end{array}$ \\
\hline Língua Portuguesa & $\begin{array}{l}\text { Leitura, exploração e produção textual; exploração oral; "contação" de } \\
\text { histórias; criação de painéis; produção de vídeos e jornais. }\end{array}$ \\
\hline Ciências & $\begin{array}{l}\text { Diminuição da poluição; tratamento de esgoto; poluentes da água e do } \\
\text { solo; consequências dos impactos ambientais; ecologia, cadeia alimentar, } \\
\text { evolução; seleção natural; transgênicos; relações familiares; reprodução. }\end{array}$ \\
\hline Matemática & $\begin{array}{l}\text { Tempo de degradação dos materiais; porcentagens; sinalização, dados } \\
\text { quantitativos; medidas de capacidade; proporção. }\end{array}$ \\
\hline Inglês & $\begin{array}{l}\text { Criar frases em inglês sobre o tema; vocabulários novos; identificação de } \\
\text { lugares e espaços. }\end{array}$ \\
\hline História & $\begin{array}{l}\text { Evolução; leis sobre meio ambiente; relações sociais; questões } \\
\text { socioeconômicas e socioculturais; países em desenvolvimento; dados } \\
\text { mundiais sobre poluição, degradação ambiental. }\end{array}$ \\
\hline Geografia & $\begin{array}{l}\text { Recursos hídricos; assoreamento dos rios; desmatamento; erosão; } \\
\text { equilíbrio ecológico; solos; diferentes tipos de agricultura; variações } \\
\text { climáticas. }\end{array}$
\end{tabular}

Fonte: Dados da pesquisa.

Deste modo, o trabalho, quando de forma transversal, busca a transformação dos conceitos, a explicitação de valores e a implementação de ações voltadas à construção do conhecimento, vinculados à realidade da sociedade, passa-se a ter condições de efetivar a formação de cidadãos mais participantes. Quando cada professor, dentro da especificidade de sua área, contempla o tema Meio Ambiente, de forma transdisciplinar, demonstra o quanto o presente assunto é amplo e possui diversas faces a serem exploradas (KONFLANZ, FREITAS, 2015). 


\section{Contexto discente: as transformações necessárias em prol do ambiente}

A escola, sendo uma fonte de múltiplos saberes, trata-se de um espaço sustentável e apto a trabalhar questões sociais e ambientais quando possibilita que os educandos se percebam enquanto integrantes do processo formativo.

Agregar às atividades diárias atitudes voltadas à preservação do meio ambiente é agente transformador para sua realidade. Atividades práticas permitem que o aluno seja o construtor de seu próprio conhecimento. Segundo Freire (2011), existe a necessidade de envolvimento do aluno com a atividade proposta, para que o conhecimento possa ser construído, a partir de atuações concretas.

A atividade proposta para os estudantes aconteceu em etapas diferenciadas, visando uma formação abrangente e de simples compreensão. Foram 117 (cento e dezessete) estudantes que responderam às perguntas iniciais de coleta de dados, de forma lúdica, questões de múltipla-escolha. A utilização de questionário lúdico foi uma escolha metodológica em virtude das diversas idades dos alunos que participaram, o que requereu um método que atendesse a capacidade compreensiva das idades cronológica e escolar.

Com efeito, da análise das respostas aos questionários respondidos, observou-se que $50,42 \%$ (cinquenta vírgula quarenta e dois por cento) dos participantes não sabe definir o conceito GA, porém $52,14 \%$ (cinquenta e dois vírgula catorze por cento) dos estudantes afirmaram que sua escola realiza palestras, encontros ou atividades sobre o tema GA.

A maioria dos estudantes indicou que participam de atividades sobre GA em sala de aula $(67,52 \%)$.

Acerca da realização de ações de GA em casa, não se pode indicar diferenças significativas entre as respostas sim e não. Ainda, quando questionados se sua família realiza algum reaproveitamento de resíduos (lixo), a maioria dos alunos respondeu que sim, correspondendo a 61,54\% (sessenta e um vírgula cinquenta e quatro por cento).

Durante a sondagem prévia, realizada com os estudantes, embora identificado que a escola oportunizasse momentos de reflexões acerca da temática Meio Ambiente, o termo GA não foi bem definido, as questões de natureza foram trabalhadas em ações isoladas e apenas uma parte da comunidade escolar foi realmente atingida.

Verificou-se que os conceitos sobre GA e EA, são entendidos como sinônimos, o que gera certa confusão no entendimento sobre o SGA. Nesse sentido, retoma-se que, conforme Carvalho (2012), a EA é um elemento de transformação social, baseada no diálogo, no exercício da cidadania, no fortalecimento dos sujeitos e na compreensão do mundo em sua complexidade e da vida em sua totalidade. Muitos ainda a confundem com transmissão de conhecimentos ecológicos, trazendo para a sala de aula, apenas, um enfoque restrito. 
Para Maturano (2010), a GA vislumbra práticas que permitam a conservação e a preservação da biodiversidade e a redução dos impactos ambientais provocados pelo homem, por meio da reciclagem de matériasprimas. O SGA pode estabelecer ferramentas de melhoria nas instituições, sensibilizando os sujeitos sobre a complexidade dos problemas ambientais. Além disso, nas escolas o SGA pode ser usado de forma mais flexível, fornecendo informações e propondo ações práticas que auxiliem a comunidade escolar na melhoria e manutenção do ambiente (HERCULANO, 2000).

Percebe-se que, mesmo com significados diferentes, estes temas relacionam-se entre si, em prol de um fim único: a sensibilização e preservação ambiental. Travassos (2006) afirma que a EA tem que ser desenvolvida como uma prática diária, para a qual todos os envolvidos, enquanto cidadãos devem ser orientados a adotar. Afinal, são comportamentos que impedirão que o meio ambiente, pela ação do próprio homem, torne-se impróprio para a vida.

Portanto, os índices apresentados na pesquisa, comprovam a ideia de que as práticas de GA, como o reaproveitamento e reciclagem de resíduos, estão sendo introduzidas no cotidiano das famílias, num processo educativo, gradativo e ainda lento.

Nesta perspectiva, as turmas, organizadas por ciclos, foram encaminhadas para uma breve fala, com apresentação de slides e vídeos sobre Meio Ambiente, preservação ambiental, resíduos, reaproveitamento de lixo, objetos recicláveis, hortas verticais, papel reciclado e reaproveitamento de óleo de cozinha.

As turmas foram sorteadas aleatoriamente para a participação em três oficinas práticas realizadas, as quais foram denominadas como: "Papel Semente: plante essa ideia"; "Horta Vertical: uma ideia sustentável"; e, "O que fazer com óleo de cozinha usado? SABÃO".

Dentre as três práticas, a fabricação do sabão foi escolhida para mobilizar a comunidade escolar, efetivando o SGA na escola. Nesta atividade, em que vizinhos da escola que doaram o óleo de cozinha usado para a fabricação, participaram uma turma de cada ciclo: uma classe fez o sabão; outra fez o preparo e embalagem para distribuição; outra turma, utilizando os papeis reciclados, especificamente o papel semente confeccionado na oficina anterior, produziu pequenos lembretes sobre preservação ambiental e reaproveitamento e óleo de cozinha. Os lembretes foram entregues junto com o sabão para a comunidade escolar externa.

Vale ressaltar que o descarte de resíduos sólidos tem, em sua maioria, materiais recicláveis, como garrafas, latas, papel, vidros, entre outros, que podem ser transformados e reutilizados na fabricação de novos produtos. Em que pese o óleo de cozinha esteja entre os materiais mais difíceis de serem reciclados, conforme Neto e Pino (2011) podem ser reaproveitados para fabricação de sabão.

Nesse sentido, por meio dos resultados obtidos nas práticas, entendese que a reciclagem é a forma mais adequada para minimizar o montante de Revbea, São Paulo, V. 12, № 2: 184-198, 2017. 
resíduos produzidos pelas atividades humanas, pois o material reaproveitado retoma sua função, auxiliando na solução dos problemas relacionados ao excesso de lixo.

Em momento posterior às atividades práticas, foi aplicado um questionário final sobre GA e SGA. O mesmo foi respondido por uma amostragem de 65 (sessenta e cinco) alunos, de diferentes turmas, havendo representantes de cada ciclo supracitado. O número de questionários respondidos nesta etapa diferiu em quantidade do primeiro, pois houve significativa ausência de estudantes na escola neste dia.

Analisando as respostas dos 65 (sessenta e cinco) questionários finais respondidos, observou-se que $85 \%$ (oitenta e cinco por cento) dos participantes, compreendem o significado do termo GA por meio das atividades vivenciadas na escola e $88 \%$ (oitenta e oito por cento) afirmaram que as ações desenvolvidas com o trabalho, fizeram refletir sobre o tema GA.

Quando questionados se haviam relatado para seus familiares e amigos sobre o projeto de GA que participaram na escola, $80 \%$ (oitenta por cento) responderam que sim e $74 \%$ (setenta e quatro por cento) indicaram que suas famílias passaram a adotar práticas de reciclagem e reaproveitamento de materiais.

Foi de $86 \%$ (oitenta e seis por cento) o percentual de que reaproveitamento de óleo de cozinha na fabricação de sabão permitiu aos estudantes conhecer uma forma de GA.

Questionados se desejariam participar de outras oficinas com propostas relacionadas à GA, o feedback positivo foi praticamente unânime, com percentual de $97 \%$ (noventa e sete por cento).

Um dos principais objetivos da GA deve ser a mudança comportamental, pessoal e social do homem, principalmente no gerenciamento correto dos resíduos, contribuindo com ações eficazes, mudando conceitos e atitudes. As concepções sobre EA, aliadas à formação de cidadãos preparados e comprometidos com a natureza, ganham suporte nas afirmações de Reigota (2010), pois os indivíduos e os grupos ao adquirirem sentimentos e valorização social, apresentam interesse pelo meio ambiente e vontade de contribuir para a sua proteção e qualidade.

Minc (2005) e Krasilchik (2005) quando pontuam sobre EA na escola, apontam que estes espaços devam funcionar como polos irradiadores da sensibilização ecológica, envolvendo as famílias e a comunidade, corroborando com os resultados apresentados.

Portanto, a EA deve ter um enfoque global e integrado, não podendo ser reduzida a uma única disciplina escolar, devendo ser responsabilidade de toda a escola e permear todo o currículo escolar, visando, em última instância, que a toda a comunidade se envolva e se estruture para adaptação à nova realidade. 
Os dados demonstram que as ações desenvolvidas na escola foram sementes plantadas em solo fértil, pois crianças e jovens, quando bem orientados, são disseminadores de boas ideias e de ações concretas em prol da preservação ambiental.

\section{Conclusões}

Observa-se que dos dados apontados pela presente pesquisa, destacando que tais considerações são pertinentes ao local e ao contexto de sua aplicação, pode-se aferir que a temática ambiental, embora muito discutida e trabalhada na escola participante da pesquisa, ainda relegava somente à ocasião de eventos específicos e esporádicos, como por exemplo, semana do meio ambiente ou dia da água, as atividades de EA.

Verificou-se que, a maioria dos profissionais de educação da escola participante se encontrava distante da realidade demonstrada com 0 desenvolvimento do trabalho, sobre GA na escola, transparecendo conhecimentos superficiais e necessitando de formações continuadas mais frequentes, como as atividades aqui propostas, no intuito de garantir a atualização e complementação teórico-prática.

Para os estudantes, as informações apresentadas pelas oficinas geraram inquietação e surpresa, o que se trata de indicativo para viabilizar e estimular maior interesse por ações de preservação dos recursos naturais.

Constatou-se, também, grande entusiasmo dos estudantes durante as práticas ao compreenderem a possibilidade da transformação do "lixo" em algo reaproveitável. Além disso, foi possível verificar que alunos e pais tem conhecimento sobre a importância da reciclagem do lixo, mas que em virtude da ausência de hábitos rotineiros, não a fazem de forma satisfatória.

Quanto à comunidade escolar, esta demonstrou não possuir conhecimento suficiente sobre GA, mesmo tendo consciência da importância da preservação ambiental.

Tornando, assim, significativa e satisfatória a inserção de atividades de GA, por meio de um planejamento organizado, cooperativo, consciente e qualificado, dentro e fora do ambiente escolar, seja em momentos teóricopráticos com os alunos e professores, seja em reuniões formativas com pais e comunidade.

Neste sentido, ressalta-se que a EA contribui para a GA e que esta contribui para tornar a sociedade mais consciente e ecologicamente justa, possuindo como suporte a solidariedade, o respeito e o amor, entre seus iguais e com todos os demais seres vivos.

\section{Agradecimentos}

À Escola Municipal de Ensino Fundamental Mariúza Silva da Silva, pelo apoio na realização do trabalho. 


\section{Referências}

ANDRADE, J.C.S.; Marinho, M.M.O.; Kiperstok, A. "Política ambiental Focada na Produção Limpa: Elementos para a Discussão Com os Setores Produtivos. Disponível em http://www.simpep.feb.unesp.br/anais8/ana8c.html.

BARBIERI, J.C. Gestão Ambiental empresarial: conceitos, modelos e instrumentos. São Paulo, Saraiva, 2011.

BRISOLARA, L.S.; SILVA, V.C.; CARDOSO, N.S. Journal of Environmental Management and Sustainability. Revista de Gestão Ambiental e Sustentabilidade. v. 5, n.2, 2016.

CARVALHO, I.C.M. Educação ambiental: a formação do sujeito ecológico. São Paulo, Cortez. 6ª ed., 2012.

CUNHA, M.I. A docência como ação complexa: o papel da didática na formação dos professores. In: ROMANOWSKI, J.; MARTINS, P.L.; JUNQUEIRA, S. (Org.) Conhecimento local e conhecimento universal: pesquisa, didática e ação docente. Curitiba, Champagnat, 2004. v.1 p.31-42 2016.

FEHLBERG, E.B.; HÖHER, B. G.; FERRARO, C. S. Educação Ambiental: Um processo coletivo para estimular habilidades, competências e valores sociais por meio de uma Unidade de Aprendizagem. Anais do 4ํ Congresso Internacional de Tecnologias para o Meio Ambiente. Bento Gonçalves-RS, Brasil, abril de 2014.

FREIRE, P. Pedagogia da Autonomia-saberes necessários à prática educativa. São Paulo, Paz e Terra, 2011.

HERCULANO, S.C. Sociologia ambiental: origens, enfoques metodológicos e objetos. Mundo \& vida: alternativas em estudos ambientais. v. 1, n.1/2, 2000.

KONFLANZ, T.; FREITAS, N. A Educação Ambiental Inserida No Licenciamento. Monografias Ambientais. p. 180-187, 2015.

KRASILCHIK, M. Prática de Ensino de Biologia. São Paulo, Editora da Universidade de São Paulo, 2005.

LOUREIRO, C.F.B.; LAYRARGUES, P.P.; CASTRO, R.S. (orgs.). Educação ambiental: repensando o espaço da cidadania. São Paulo: Cortez, 2002.

MATURANO, N.M.P.; VIEIRA, A. . Gestão Ambiental, Possibilidades para área degradada. Curso de Administração. Faculdade Cenecista de Capivari CNEC, 2010.2 Disponível em: <http://webcache.googleusercontent.com/search?q=cache:dgSdsqQyLpMJ:ww w.cneccapivari.br/libdig/index.php\%3Foption\%3Dcom rubberdoc\%26view\%3D doc\%26id\%3D225\%26format\%3Draw+\&cd=1\&hl=pt-BR\&ct=clnk\&gl=br> Acesso em: 05 de março de 2017.

MINC, C. Ecologia e Cidadania. São Paulo, Moderna, 2005. 
MORIN, E. Ciência com consciência. Rio de Janeiro, 8aed, Bertrand Brasil, 2005.

NÓVOA, A. Professores: Imagem do futuro presente. Lisboa, Educa, 2009.

NETO, O. G. Z.; PINO, J. C. Trabalhando a química dos sabões e detergentes. Porto Alegre: Universidade Federal do Rio Grande do Sul, 2011. Disponível em: $<$ http://www.iq.ufrgs.br/aeg/html/publicacoes/matdid/livros/pdf/sabao.pdf> Acesso em: 04 de março de 2017.

NUNES, D.S.; CARVALHO, C.M. Educação Ambiental e a Interdisciplinaridade da Gestão Ambiental. Revista Eletrônica em Gestão, Educação e Tecnologia Ambiental. v.18, n.3, p 1093-1100, 2014.

REIGOTA, M. Meio ambiente e representação social. São Paulo, Cortez, 2010.

RODRIGUES, A.M.; MENEZES, J.B.F.; ARAUJO, M.V.R.; ABREU, M.K. F. Gestão Ambiental na Educação Básica: A realidade de escolas da rede estadual de ensino em Iguatu, Ceará, Brasil. Electronic Journal of Management, Education and Environmental Technology. v. 20, n. 1, p. 4049, 2016.

SEVERINO, A.J. Pressupostos filosóficos da formação e da prática do educador. Cadernos de Educação. Pelotas, v.15, n. 27, p.37-54, 2006.

SCHWERZ V.L. Aplicação de sistema colaborativo à gestão pública municipal: o reaproveitamento do óleo de cozinha, 2016. Artigo científico apresentado ao departamento de gestão pública da Universidade Estadual de Maringá.

SILVA, H.O.O. A importância da educação ambiental no âmbito escolar. Revista Interface. n. 12, p. 163-172, 2017.

TEIXEIRA, L.I.L.; FILHO, J.C.L.S.; MEIRELES, F.R.S. Consciência e Atitude ambiental em estudantes de Instituições de Ensino Técnico e Tecnológico. Revista Eletrônica em Gestão, Educação e Tecnologia Ambiental. v.20, n. 1, p 334-350, 2016.

TRAVASSOS, E.G. A prática da educação ambiental nas escolas. Porto Alegre, Mediação, 2006.

VENZKE, C.S.; NASCIMENTO, L.F.M. Caminhos e desafios para a inserção da sustentabilidade socioambiental na formação do administrador brasileiro. Revista de Administração Mackenzie. v.14, n.3, p.26-54, 2013. 